Article

\title{
Study of Cement-Based Superhydrophobic Composite Coating: New Option for Water Drainage Pipeline Rehabilitation
}

\author{
Tianyu Wang and Cong Zeng * \\ Department of Engineering, China University of Geosciences, Wuhan 430074, China; cugwty@cug.edu.cn \\ * Correspondence: zengcong@cug.edu.cn
}

Received: 2 October 2020; Accepted: 28 October 2020; Published: 6 November 2020

\begin{abstract}
A great number of urban underground concrete water drainage systems in China are facing challenges of corrosion, blockage, and leakage. This could result in engineering accidents such as urban inland inundation, pipeline collapse, leakage, and blockage. The common contributing factors for pipeline leakage and blockage are the porous structures and the perishable surfaces of concrete pipes. To address these issues, we synthesized superhydrophobic coating materials such as $\mathrm{SiO}_{2}$ aerosol, bisphenol A diglycidyl ether (DGEBA), and N- $\beta$-aminoethyl- $\gamma$-aminopropyltrimethoxysilane (AEAPTS). Our superhydrophobic coating on cement-based surfaces presents good waterproof ability, mechanical stability, and self-cleaning properties. Test results show that the superhydrophobic coating exhibits higher water discharge capacity and survivability to corrosive underground water drainage pipeline environments. Hence, this $\mathrm{SiO}_{2}$ aerosol @ bisphenol A diglycidyl ether coating possesses enormous potential in surface modification of pipeline rehabilitation materials.
\end{abstract}

Keywords: superhydrophobicity; $\mathrm{SiO}_{2}$ aerosol @ bisphenol A diglycidyl ether coating; water drainage pipe; cement-based materials

\section{Introduction}

Many infrastructures in China are in a severely poor condition, making rehabilitation work desperately needed. This situation is worse in the underground structures, which are facing harsh working environments such as water infiltration, corrosive soil, and disturbing loads. The deterioration of cement-based materials would be accelerated when water and other chemicals penetrate the pores of the matrix [1]. Most of the water drainage pipes in China have problems with leakage, corrosion, and structural instability, which could result in wasting resources, environmental pollution, and a great loss of social-economic benefit [2,3]. To address these issues, many trenchless methods have been widely used such as cured-in-place pipes, sealers, and coatings [4]. The coating method is getting more and more attention in the field because of its effective construction, economic friendliness, and wide applicability [5]. Among those existing coating materials, fiber-reinforced cement mortar and epoxy resin material can together help to provide structural support, controlling the water quality while showing good compatibility with original materials [6,7]. However, corrosion resistance has always been a major problem in water drainage pipeline rehabilitation as the cement-based repairing liner is prone to corrosion again. What is more, the cement-based coating will reduce the inner diameter of the pipe, leading to flow loss [4]. Therefore, the surface corrosion resistance and discharge capacity of the repairing material are the key elements of the rehabilitation work.

The $\mathrm{SiO}_{2}$ aerogel was widely used as the modifier in cement-based materials [8], and previous studies demonstrated the influence of $\mathrm{SiO}_{2}$ aerogel on durability, density, mechanical properties, thermal conductivity, and other properties of the concrete mixture $[9,10]$. However, it seems to only 
delay the corrosion to a certain extent rather than insulate it. The concept of superhydrophobic hybridization incorporates biomimicry (lotus effect) with a water contact angle (WCA) greater than $150^{\circ}$ and a sliding angle (SA) less than $10^{\circ}$, mimicking lotus leaves and water striders, which have gained attention from people in the superhydrophobic field [11-14]. Superhydrophobic coatings enable engineers to improve the durability, self-cleaning, and discharge capacity of cement-based materials, thus effectively reducing the damage caused by the all-pervasive corrosive fluid and dirt in sewage environments [15-18]. Among those techniques such as the hydrothermal technique [19], etching [20], assembling [21], phase separation [22], chemical vapor deposition [23], and electrochemical [24], the coating is the simplest and most economical option, making it an exemplary candidate for engineering practice [25]. A variety of experiments were performed to create the superhydrophobic surface and the characteristics such as durability, frost-resistance, and abrasive resistance generated enormous research interest. For example, Wong et al. designed a waterproof concrete by using the superhydrophobic paper sludge ash [26]. Husni et al. extracted the silica nanoparticles from rice husk ash and created a superhydrophobic coating that improves the anti-permeability of the concrete [18]. She et al. fashioned a mechanically durable superhydrophobic concrete surface by a direct spraying method [27]. Arabzadeh et al. coated the concrete substrates by using the layer-by-layer deposition technique [28]. Young et al. found that the friction responses and roughness of monodispersed coatings were lower than those of hierarchically structured coatings [29].

However, not enough research has been laid on the real-world applications of superhydrophobic cement-based materials under complex working conditions. For example, there is very limited working space in underground water drainage pipeline rehabilitation work, which means that the superhydrophobic coating should be combined with the trenchless method [2]. The resistance of the coating to corrosive flow and the impact the coating might have to the cement-based rehabilitation material should also be considered [3,4].

In our current study, we utilized a nontoxic method to fashion a fiber-reinforced cement mortar surface modified by a $\mathrm{SiO}_{2}$ aerosol @ bisphenol A diglycidyl ether hierarchically structured coating. This superhydrophobic coating consisted of pipeline structure rehabilitation materials possessing good mechanical, antifouling, discharge capacity, and corrosion resistance while the superhydrophobic modification had few impacts on the mechanical performance of the rehabilitation materials. This simple, effective, and economical method can be operated in a beaker, and the anti-corrosion property and mechanical durability of the coating were demonstrated when exposed to special conditions mimicking those of underground water drainage pipelines. Our findings provide significant insight into the application of superhydrophobic materials in trenchless rehabilitation work.

\section{Materials and Methods}

\subsection{Cementitious Materials}

In the study, the $40 \times 12$ Kuralon K-II PVA fibers (diameter: $40 \mu \mathrm{m}$, length: $12 \mathrm{~mm}$ ) from Kuraray (Tokyo, Japan) were used. This kind of fiber has a 1.6 GPa tensile strength and Young's modulus of more than $38 \mathrm{GPa}$. Another component of the pipeline repairing fiber-reinforced cement mortar mixtures was Portland cement from Longlin Cement (Longyan, China) conforming to ASTM C150 [30]. Fly ash was from Newreach Materials (Wuhan, China) and the chemicals were $\mathrm{SiO}_{2}(58 \%), \mathrm{Al}_{2} \mathrm{O}_{3}(30 \%)$, $\mathrm{Fe}_{2} \mathrm{O}_{3}(4.3 \%), \mathrm{CaO}(1.5 \%), \mathrm{MgO}(2.8 \%)$, and $\mathrm{Na}_{2} \mathrm{O}(3.2 \%)$. Silica sand (Hengwang Environmental Protection, Zhengzhou, China) with a $\mathrm{SiO}_{2}$ content more than $99.3 \%$ and an average particle size of $0.5 \mathrm{~mm}$ was used. The polycarboxylate superplasticizer was from SUNBO (Suzhou, China) with a water-reducing effect of $30 \%$.

\subsection{Coating Materials}

The silane coupling agent (AEAPTS) was bought from Aladdin (Shanghai, China); bisphenol A, epichlorohydrin, and the curing agent were provided by RESIPLAST PROTECT (Antwerp, Belgium) and 
XIAMEN ANYUE (Xiamen, China); $38 \%$ hydrochloric acid ( $\mathrm{HCl}$ ), absolute ethyl alcohol, $\geq 28 \%$ ammonium hydroxide, and 97\% sheet sodium hydroxide were bought from Xilong Scientific Co., Ltd.(Guangdong, China); $\mathrm{SiO}_{2}$ aerogel materials were bought from Pomeloking Eco-Technologies (Qingyuan) Co., Ltd. (Qingyuan, China).

\subsubsection{The Synthesis Method of $\mathrm{SiO}_{2}$ Aerogel Superhydrophobic Powder}

One of the important influences on the superhydrophobicity of the coating is the mass ratio of $\mathrm{SiO}_{2}$ aerogel and AEAPTS. Hence, five different solutions were designed, as shown in Table 1, to evaluate this influence. First, ethyl alcohol $(5 \mathrm{~mL})$ and $\mathrm{SiO}_{2}$ aerogel were added into a beaker at the same time and stirred for $1 \mathrm{~min}$. Then, AEAPTS was put into the solution with $10 \mathrm{~min}$ of stirring. A certain amount of ammonium hydroxide was added drop-by-drop into the beaker to promote the hydrolysis reaction of the AEAPTS and make the solution gel. It was designed to keep stirring for more than $6 \mathrm{~h}$ to prepare the colloidal solution successfully.

Table 1. Experimental design for superhydrophobic colloidal solutions.

\begin{tabular}{cccc}
\hline Specimen ID & AEAPTS/g & SiO $_{2}$ Aerogel/g & Ethyl Alcohol/mL \\
\hline 1 & 0.1 & 0.5 & 5 \\
2 & 0.2 & 0.5 & 5 \\
3 & 0.3 & 0.5 & 5 \\
4 & 0.4 & 0.5 & 5 \\
5 & 0.5 & 0.5 & 5 \\
\hline
\end{tabular}

The colloidal solution was dripped into glass substrates to be evenly spread. Then, the samples were put into an oven and dried at $60^{\circ} \mathrm{C}$ for $6 \mathrm{~h}$ until the ethanol completely evaporated, and after that, the residue was ground into powders and collected.

\subsubsection{Fabrication of $\mathrm{SiO}_{2} @$ DGEBA Superhydrophobic Coatings}

The curing agent and DGEBA (1:2) were put into a certain amount of ethanol together to prepare a $3 \%$ DGEBA solution with 5 min of stirring. After that, the solution was sprayed evenly onto the cement specimens' surfaces as the adhesive. Then, the superhydrophobic powder ( $0.3 \mathrm{~g}$ per time) was laid evenly om the adhesive layer 3-5 times after $30 \mathrm{~min}$, and the excess blown off by a blower. After the composite material was bone dry, a superhydrophobic coating was formed on the surface of the matrix.

\subsection{Cement Samples}

The cement specimens were produced at a water-cement ratio of 0.30 and a sand-cement ratio of 0.7 . The $15 \%$ cement quantity was replaced by fly ash, and the dosage of polycarboxylate superplasticizer was determined as $0.8 \%$ of the quality of cementing material. The specimens were cast in $40 \mathrm{~mm} \times$ $40 \mathrm{~mm} \times 40 \mathrm{~mm}$ cube molds. The volume ratio of PVA fibers was $1.75 \%$. These kinds of cement-based materials have been used to repair damaged water drainage pipelines in America, China, and many other countries [31]. To endow the cementitious composite with a better performance in rehabilitation work, specimens were divided into four groups (Table 2) with the surface special handing-treatment.

Table 2. Cement specimens design for durability testing.

\begin{tabular}{cccc}
\hline Specimens ID & Top Surface & The Rest Ones & Curing Environment/pH \\
\hline I & modified & Sealed & deionized water/approximately 7 \\
II & untreated & Sealed & deionized water/approximately 7 \\
III & modified & Sealed & sanitary sewage/3-5 \\
IV & untreated & Sealed & sanitary sewage/3-5 \\
\hline
\end{tabular}


Upon compaction, the samples were cured at a room temperature of $20 \pm 5{ }^{\circ} \mathrm{C}$ and relative humidity of more than $95 \%$. Then, the specimens were demolded $24 \mathrm{~h}$ later as the modification was completed. The waterproof sealant was used to ensure that the top surfaces of the cube specimens were the only area in contact with the curing environment and at which moisture ion transport occurs (see Figure 1). Several parameters were tested to observe the effect of the coating on the specimens under different curing conditions.

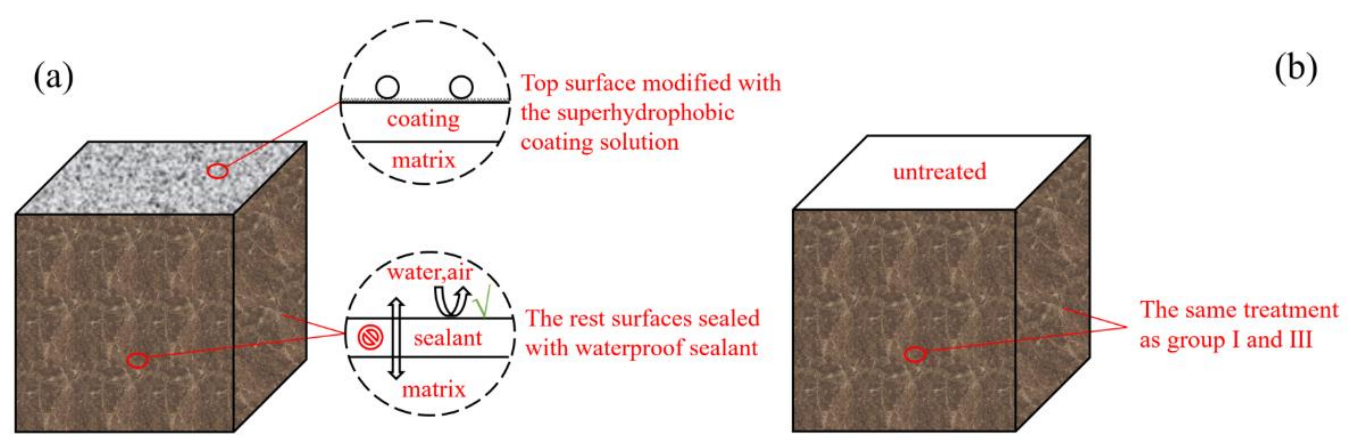

Figure 1. (a) Preparation of the treatment of the specimens in group I and III; (b) the top surfaces of specimens in group III and IV were untreated.

\subsection{Characterization Methods}

A Tecnai G2 TF20 S-TWIN (Park Systems, Suwon, South Korea) was operated at $300 \mathrm{kV}$ to carry out the transmission electron microscopy (TEM) testing. The specimens were prepared and Au-sputtered, then measured by a JSM-6701F (JEOL Ltd., Tokyo, Japan) to obtain the FESEM (field emission scanning electron microscope) images. A Thermo Scientific ESCALAB 250Xi (Thermo Scientific, Waltham, MA, USA) was used for the XPS (X-ray photoelectron spectroscopy) measurement while the excitation source was the Al Ka line. A Thermo Scientific Nicolet iS10 (Thermo Scientific, Waltham, MA, USA) was used to record the FTIR (Fourier-transform infrared spectra) spectroscopy. A JSM-5601LV SEM (scanning electron microscope, JEOL Ltd., Tokyo, Japan) was operated at $5 \mathrm{keV}$ to obtain the SEM images of platinum-plated samples. A JC2000D (Shanghai Zhongchen Technology Apparatus Co., Ltd., Shanghai, China) was used to measure the water contact angles (WCA) of different types of samples at ambient temperature. Optical photographs were taken by a Nikon D7200 (Tokyo, Japan). These experimental works were done in Hubei Key Laboratory of Polymer Materials, Hubei University (Wuhan, China).

In accordance with ASTM C109, the $40 \mathrm{~mm} \times 40 \mathrm{~mm} \times 40 \mathrm{~mm}$ cubes were tested at a $0.9 \mathrm{kN} / \mathrm{s}$ loading rate at 7, 28, 60, 90 and 120 days to obtain the compressive strength. The water absorption value and quality loss were also measured as important indicators in accordance with ASTM C642 [32].

\section{Results}

\subsection{Structure and Composition of the Adhesive}

Epoxy resin is well-known for its applications in coating, adhesives, aerospace, and the electronics industry because of its outstanding physicochemical properties [32]. DGEBA provided by RESIPLAS PROTECT (Antwerp, Belgium) and XIAMEN ANYUE (Xiamen, China) was used in this study. It was obtained through condensation of bisphenol A and epichlorohydrin under alkaline conditions. The DGBPA used in this study was opaque white pasty fluid, which turned to a whitish-gray solid after curing. The epoxy equivalent weight (EEW) and the epoxy value of the DGBPA were $210-280 \mathrm{~g} / \mathrm{mol}$ and $0.357-0.476 \mathrm{~mol} / 100 \mathrm{~g}$, respectively, and it showed a melting point of $205-272{ }^{\circ} \mathrm{C}$ and viscosity of 5000-10,000 mPa.s.

The reaction mechanism is shown in Figure 2. The special molecular structure of DGEBA gave it better mechanical property, corrosion resistance, and adhesion performances. Those advantages 
made DGEBA suitable for application in underground infrastructure rehabilitation work. The pilot experiment had been carried out to evaluate the performance of DGEBA as the adhesive.

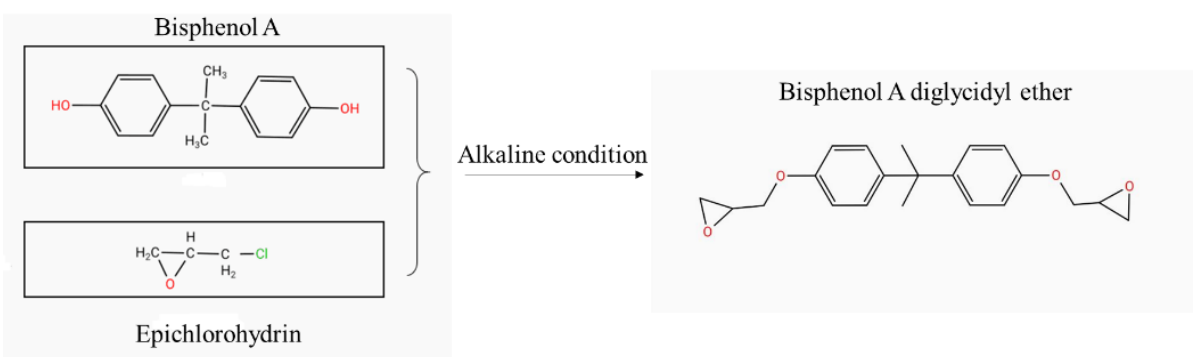

Figure 2. The reaction mechanism of bisphenol A diglycidyl ether (DGEBA).

The DGEBA could disperse uniformly in ethyl alcohol with simple stirring at room temperature, as shown in Figure 3. After drying, the DGEBA solution adhered to the matrix smoothly (Figure $4 a$ ). Figure $4 b$,c show that the superhydrophobic particles were observed on the surface of the DGEBA coating.

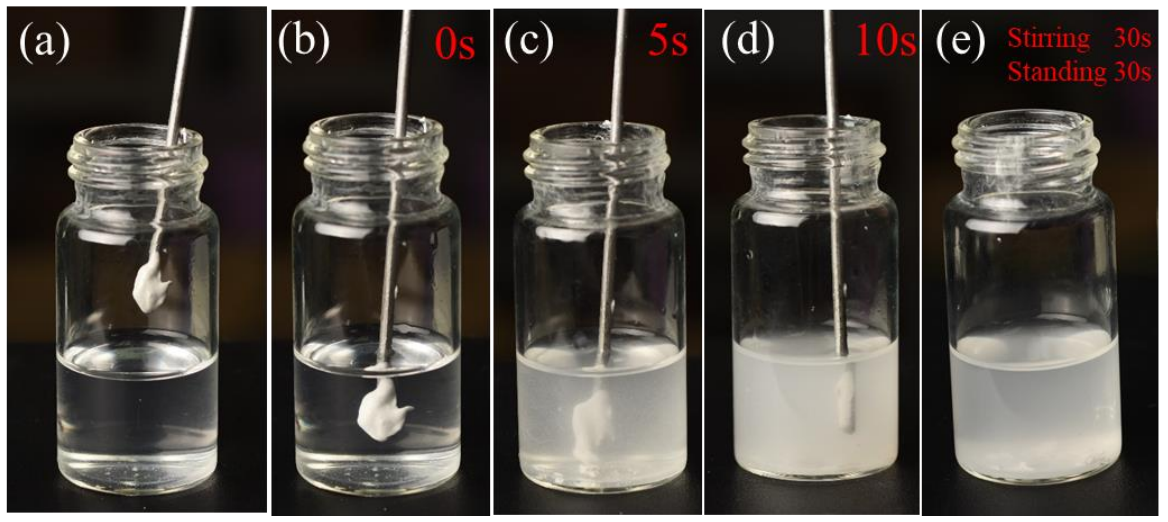

Figure 3. The first $30 \mathrm{~s}$ when DGEBA was dispersed in ethyl alcohol (a-e).

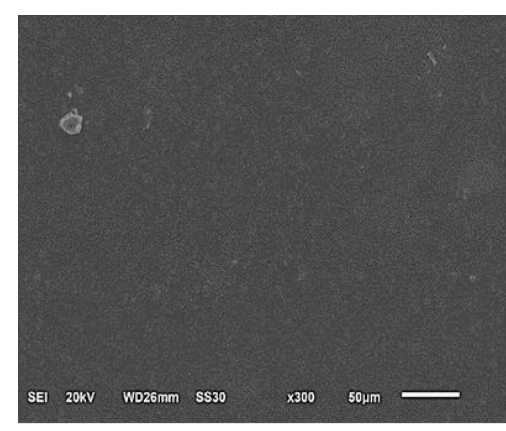

(a)

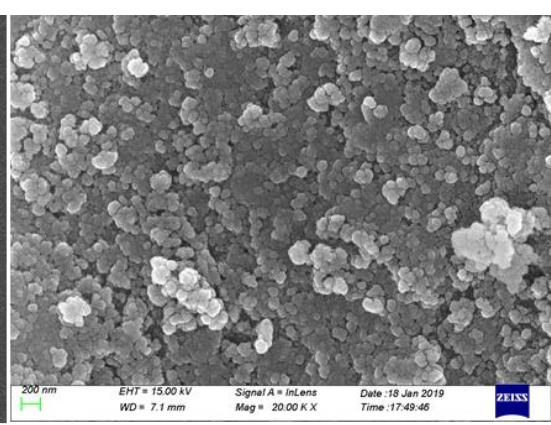

(b)

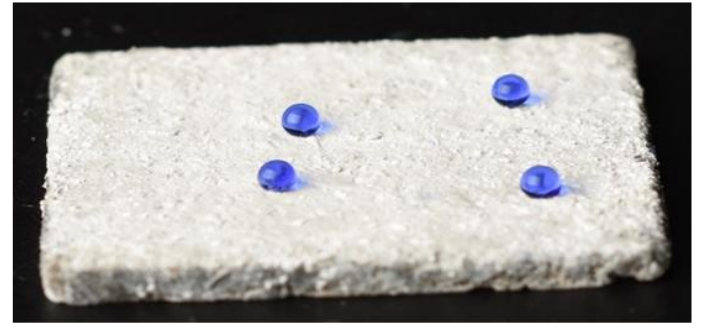

(c)

Figure 4. (a) DGEBA layer on cement sample's surface; (b) FESEM images of superhydrophobic particles on DGEBA; (c) $\mathrm{SiO}_{2}$ aerosol @ DGEBA coating. 
Results show that the DGEBA exhibited a significant performance in dispersing, film formation, and adhesion between the superhydrophobic powder and cement samples. Therefore, the DGEBA could be an ideal adhesive in the following surface modification experiment.

\subsection{Superhydrophobicity of the Modified $\mathrm{SiO}_{2}$ Aerogel Powder}

The hydrolysis reaction of the AEAPTS promoted the formation of Si-O-Si-( $\left.\mathrm{NH}_{2}\left(\mathrm{CH}_{2}\right)_{2} \mathrm{NH}\left(\mathrm{CH}_{2}\right)_{3}\right)$ linkages and showed that parts of hydrophilic groups $(\mathrm{Si}-\mathrm{OH})$ would be transformed into hydrophobic groups.

AEAPTS hydrolytic reaction generated Si-O-Si- $\left(\mathrm{NH}_{2}\left(\mathrm{CH}_{2}\right)_{2} \mathrm{NH}\left(\mathrm{CH}_{2}\right)_{3}\right)$ on the surface of the particles, which brought superhydrophobicity to the powder. Then, the papillary structure was formed when the surface of the adhesive was evenly covered by these superhydrophobic particles, increasing the roughness of the coating, as shown in Figure 5. The superhydrophobicity is attributed to the nano and microscale hierarchical structure based on the wetting theory developed by Cassie and Baxter [33].
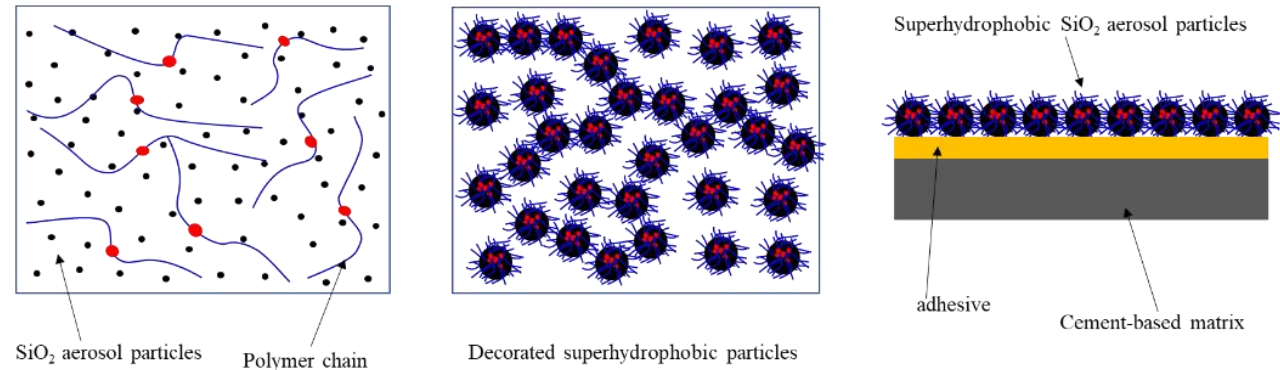

Figure 5. A schematic diagram for the preparation of compound $\mathrm{SiO}_{2} @ \mathrm{DGEBA}$ superhydrophobic coating.

TEM images (Figure 6) showed that the coating consisted of countless superhydrophobic particles, and the rough surface and the low surface energy also contributed to the superhydrophobic property.

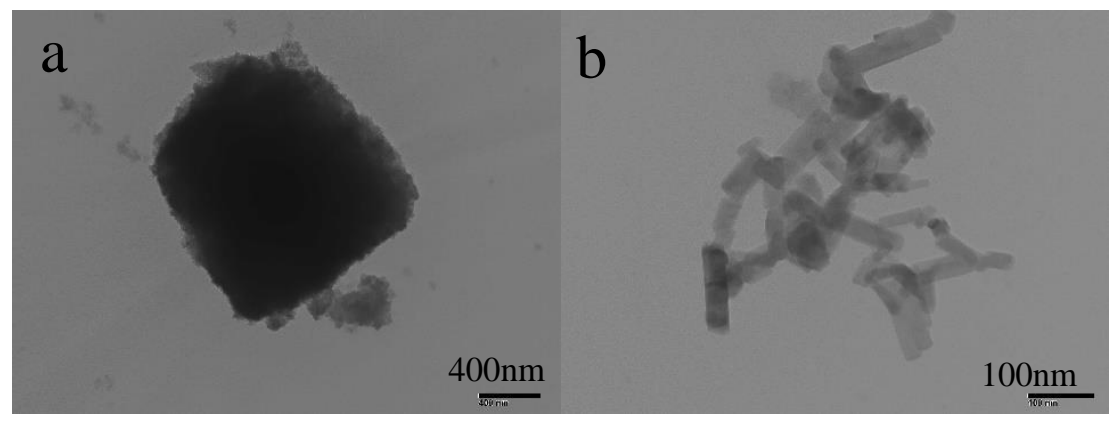

Figure 6. (a) Superhydrophobic particles with a rough surface; (b) The chain-type superhydrophobic particles.

The $\mathrm{SiO}_{2}$ aerogel superhydrophobic powder was characterized by XPS survey and FTIR analysis. The XPS image (Figure 7a) showed a peak of nitrogen around $400 \mathrm{eV}$, demonstrating that the AEAPTS had brought amino groups onto the particles. The carbon peak around $285 \mathrm{eV}$ (Figure 7a) suggested that the hydrophobic alkyl was grafted on the surface of $\mathrm{SiO}_{2}$ particles after the hydrolysis of AEAPTS. An antisymmetric stretching vibration peak of O-H was observed at $3442 \mathrm{~cm}^{-1}$ according to the FTIR spectrum (Figure $7 \mathrm{~b}$ ). The $\mathrm{Si}-\mathrm{O}-\mathrm{Si}$ skeleton structure of $\mathrm{SiO}_{2}$ aerosol was confirmed by the transmittance peaks around 1084 and $455.1 \mathrm{~cm}^{-1}$. The appearance of $\mathrm{CH}_{3}$ and C-N's peaks at 2958.4 and 1384.6/1322.9 $\mathrm{cm}^{-1}$, respectively, indicated that the hydrophilic hydroxyl had been replaced by the hydrophobic grouping, which was consistent with the results of XPS survey. This was also substantiated by the peak of Si-C at 1253 and $844 \mathrm{~cm}^{-1}$. The XPS survey and FTIR spectrum together showed that the surface of the $\mathrm{SiO}_{2}$ aerosol was covered by superhydrophobic structures that are necessary for the formation of a stable solution and superhydrophobic compound particles. 

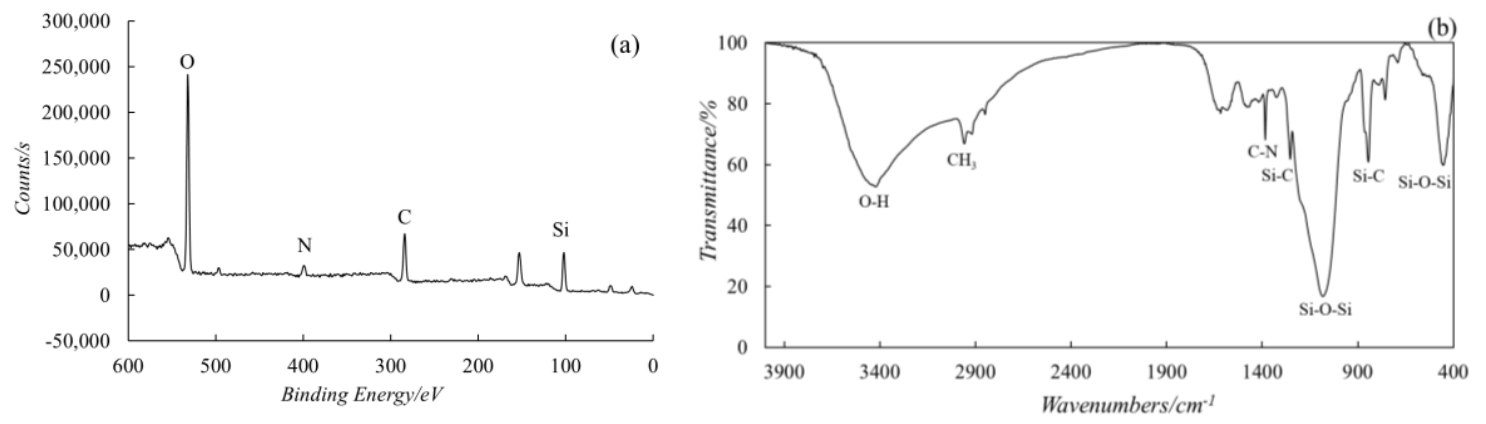

Figure 7. (a) XPS survey of the superhydrophobic particles; (b) FTIR image of the superhydrophobic particles.

Cement samples were modified by using five groups of superhydrophobic powder designed according to Table 1 and the DGEBA. The WCAs of all five samples are shown in Figure 8. Group 3 exhibited the best superhydrophobicity among all groups, with the WCA reaching $153^{\circ}$. In addition, WCA images (Figure 8) demonstrate that the appropriate mass ratio of the $\mathrm{SiO}_{2}$ aerosol and AEAPTS creates better superhydrophobicity, while too much AEAPTS might impair it.

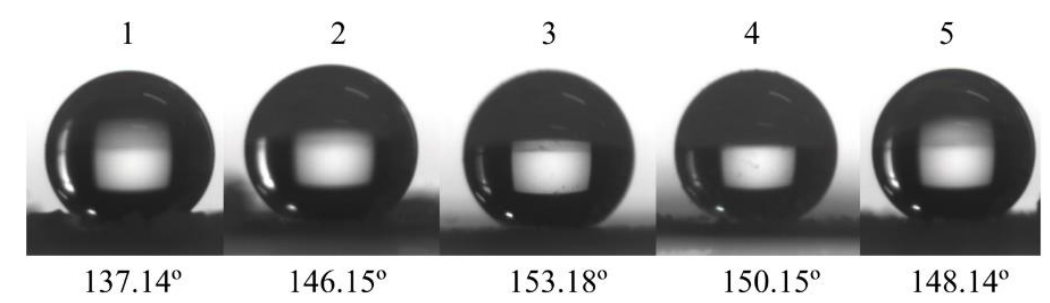

Figure 8. Water contact angle (WCA) images of five different groups.

In the quantitative testing of the different coatings' binding force and mechanical strength, sandpapers $(800 \mathrm{Cw})$ and a quantitative weight $(50 \mathrm{~g})$ were used in the tests. Figure $9 \mathrm{a}, \mathrm{b}$ showed that the modified cement sample $(40 \mathrm{~mm} \times 40 \mathrm{~mm})$ was put onto the sandpaper, and the sandpaper would directly contact the coated surface. The $50 \mathrm{~g}$ weight was added above the uncoated side and the specimen was pushed and slid slowly and evenly toward the ruler direction to $10 \mathrm{~cm}$. Then, the coatings' binding force and mechanical strength were tested by repeating the whole process several times as designed.

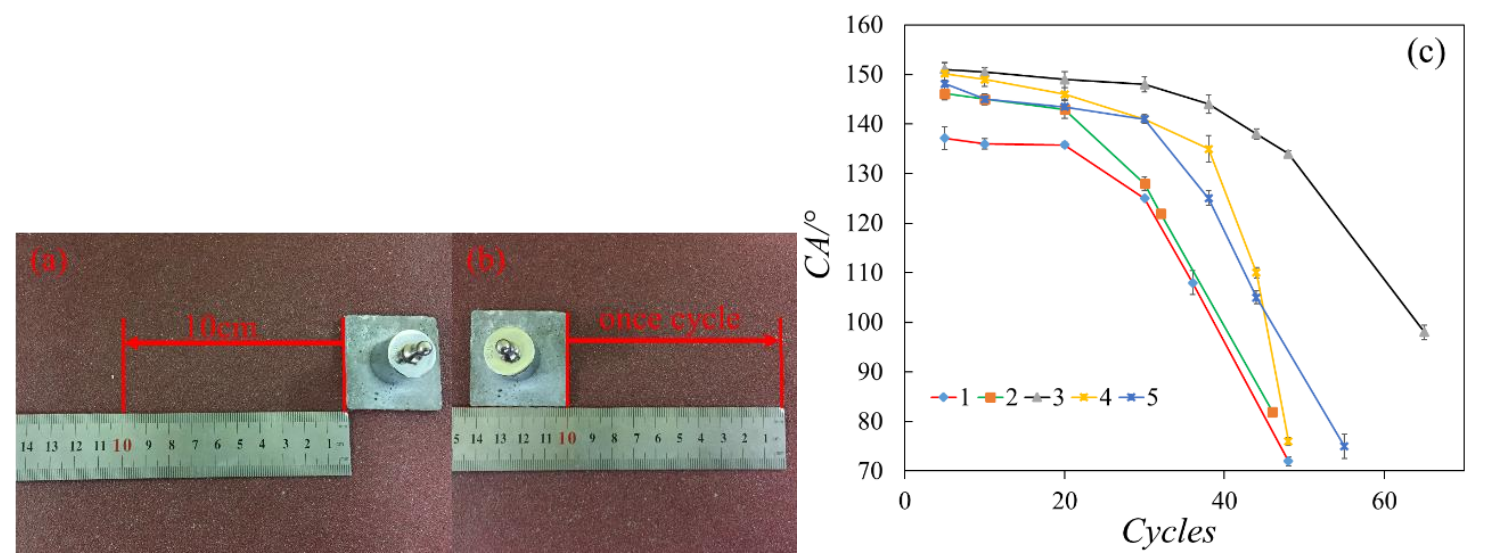

Figure 9. (a,b) Schematic image of the mechanical strength and binding force testing procedures; (c) WCA changes after friction.

Figure 9c showed that the WCA value did not decrease significantly after 20 cycles. Besides, no obvious damage on the coating surface was observed with only a small amount of powder worn 
off from the specimens. While Group 3 and 4 hold a WCA higher than $148^{\circ}$, the WCA of Group 1 decreased rapidly after 24 cycles, and the WCA in Group 2 reduced after 32 cycles. The WCA in Groups 4 and 5 sustained more than 38 cycles while Group 3 maintained a high WCA even after 50 moving cycles.

The results of the quantitative testing (Figure 9) show that the coatings' WCA was not affected by the amount of DGEBA [34], while the property of superhydrophobic powder had a significant impact on the superhydrophobicity of the coating when using the same adhesive. According to the test results, Group 3 held the best mechanical stability and superhydrophobicity, and it was chosen for the following test.

The previous study demonstrated that the water column bounces but does not wet or spread on the water-repellent surface [35], as shown in Figure 10a,b. In Figure 10c-k, we compared the water-affecting patterns between untreated and treated cement samples. Figure 10c-e illustrated that the water dropping process on the untreated cement samples surface readily wetted at the moment water droplets contacted the sample surface. The water droplet bounced off the treated surface without wetting, indicating the superhydrophobicity of the surface. The sizes of the droplets varied with random impact velocities.

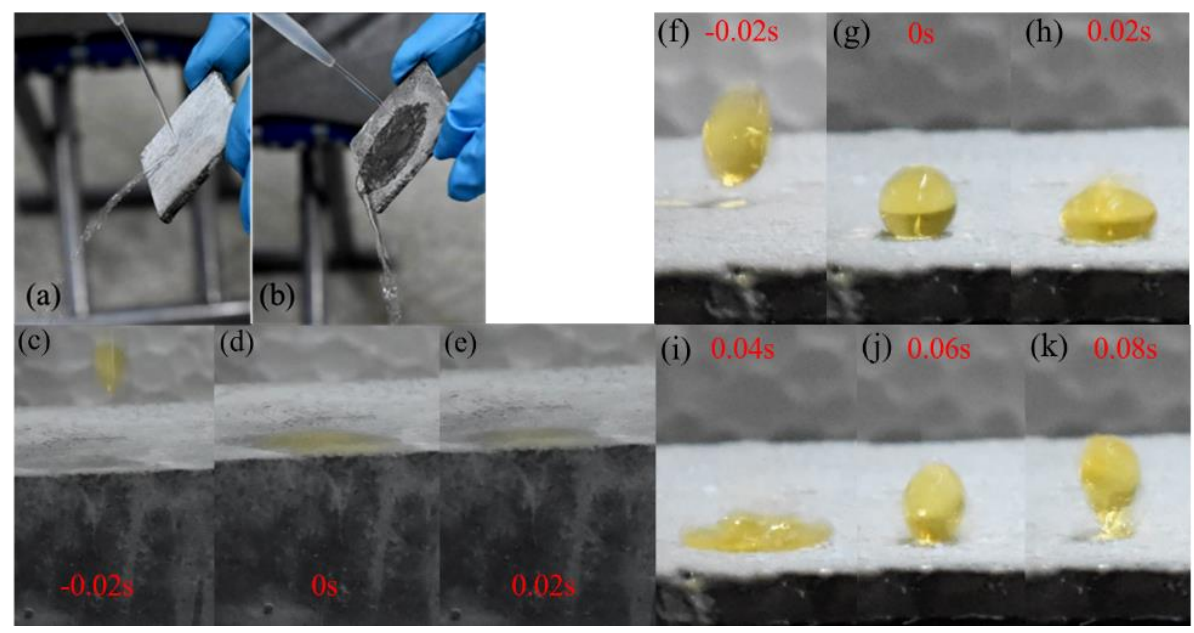

Figure 10. (a) Water column bouncing off the coated surface; (b) water column wetting the uncoated surface and spreading immediately. (c-e) Time-lapse photographs of water droplets spreading on the normal cement samples. (f-k) Time-lapse photographs of water droplets bouncing on the treated cement sample.

\subsection{Mechanical Performance and Quality Loss}

The coating material functions as a protective layer that enables the cement-based rehabilitation material to resist the negative effects of the corrosive environment. Samples were prepared and tested according to the design in Table 2. The 28d compressive strengths of the group I-IV cement samples were 91.6, 98.0, 81.6, and 62.4 MPa, respectively (Figure 11a). The average compressive strength of group III was $30.6 \%$ higher than that of group IV, while the average of group I was about $92 \%$ of that of group II.

As the change in the samples' quality was negligible in a standard environment, we focused on the differences in mass change of group III and IV (Figure 11b). Our results show that the modified samples held a better performance when curing under a corrosive environment as the quality loss was $71.4 \%(30 \mathrm{~d}), 52.4 \%(90 \mathrm{~d})$, and $41.8 \%(120 \mathrm{~d})$ lower than those of the standard samples, respectively.

The results of mechanical performance and quality loss suggest that the superhydrophobic coating provides good protection by enhancing the mechanical strength of the cement-based materials. Moreover, the modification had minimal impact on the cement samples in the standard curing environment. 

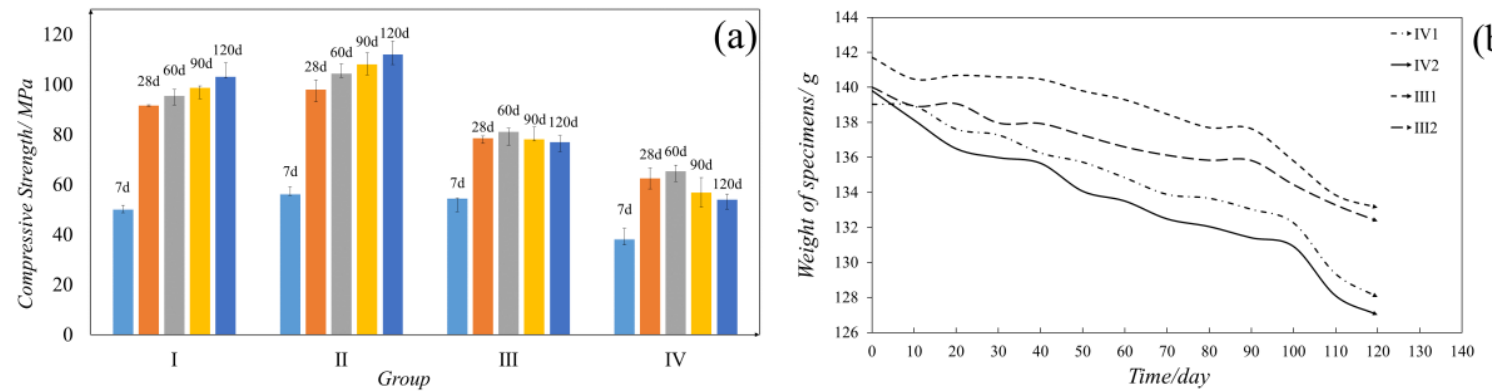

Figure 11. (a) Testing results of the cement samples' compressive strength. (b) Weight changing of the cement samples.

\subsection{Durability and Other Characteristics of $\mathrm{SiO}_{2}$ Aerosol @ DGEBA Coating}

The durability of the repairing materials has a critical influence on the long-term integrity of the infrastructures, especially with variations in temperature, humidity, and corrosive environmental factors [36,37]. Our test result shows that the DGEBA exhibits good performance in coating and adhesiveness, and it is also regarded as a durable material in practical applications.

Figure 12 shows the water droplets on a half-coating cement surface with a tilted angle of $9.82^{\circ}$. The water flowed faster on the superhydrophobic surface than the cement surface with the help of gravity. It can be seen from Figure 12 that the water droplets fell from the coating part quickly while the water stayed on the uncoated face. All the water droplets were trapped on the surface of the uncoated part while many droplets had passed through the coated part. This property of the superhydrophobic coating could significantly improve the drainage capacity of the urban drainage system, especially for those gravity pipelines [2,3].

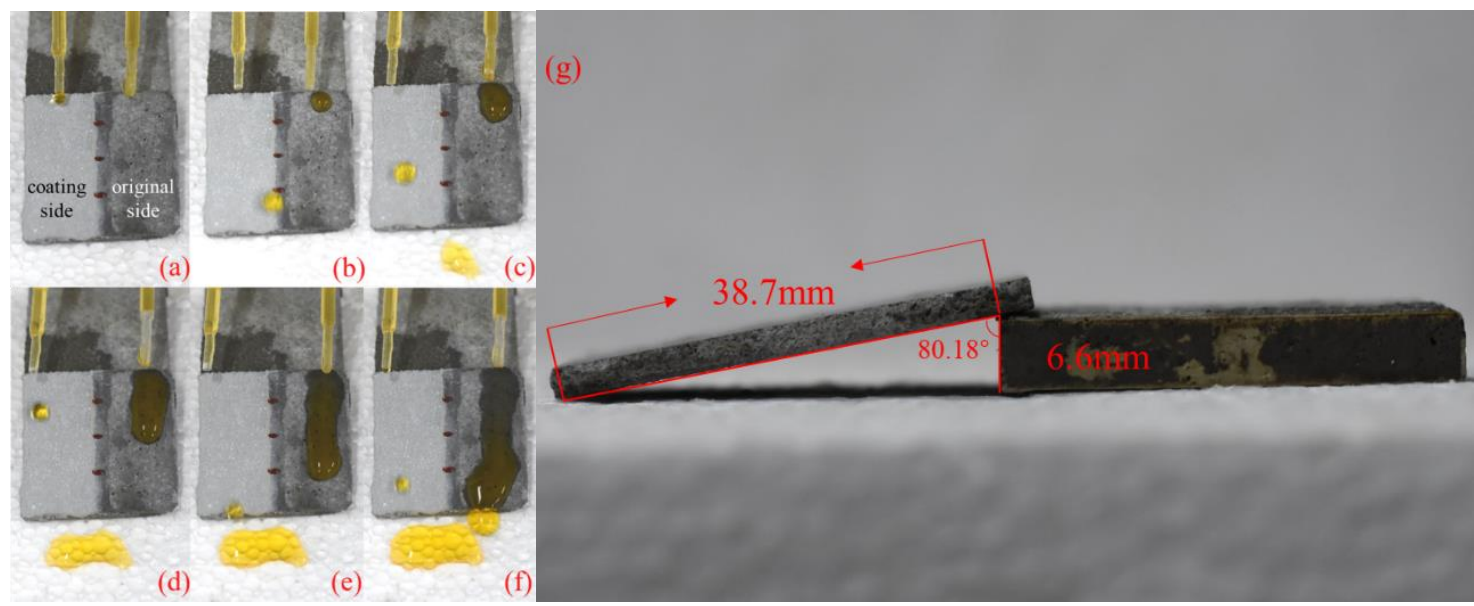

Figure 12. (a-f) The superhydrophobic surface holds a better drainage capacity compared to the untreated surface, $(\mathrm{g})$ The side view of the half-coating specimen with a title angle of $9.82^{\circ}$.

The process of self-cleaning is shown in Figure 13. It can be seen in Figure 13a-l that the coating surface was full of clouds of dust. Then, an injection syringe was used to apply water dropwise onto the surface. The uncoated surface was wetted easily and remained dirty after a 5 min washing period (Figure 13g-l). As for the modified surface, the water drops could easily remove the dust from the specimen without wetting the surface (Figure 13a,b,d,e). Figure 13c,f show that all the dust was eventually washed out with much less cleaning water, and the surface remained clean after the whole process. The surface was not damaged and stayed dry during the experimental process, which also indicated the good durability of the coating. 


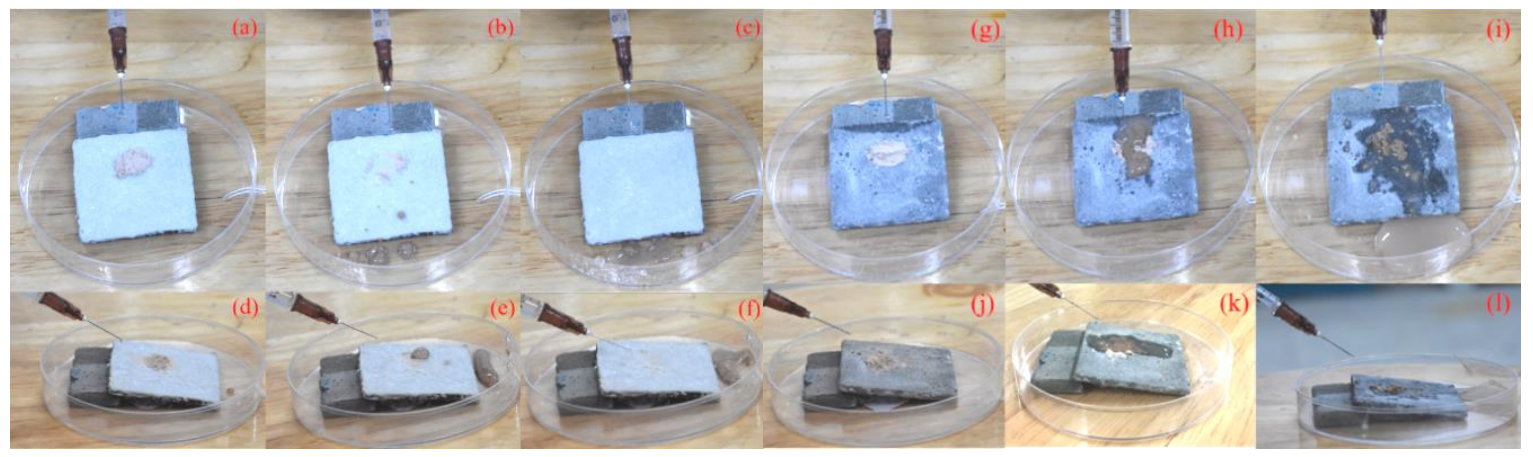

Figure 13. (a-c) The self-cleaning process on the $\mathrm{SiO}_{2}$ aerosol @ DGEBA, $(\mathbf{d}-\mathbf{f})$ : Side view of the self-cleaning process on the $\mathrm{SiO}_{2}$ aerosol @ DGEBA, (g-i): The unsuccessful process of self-cleaning on the untreated cement surface, $(\mathbf{j}-\mathbf{1})$ : Side view of the unsuccessful process of self-cleaning on the untreated cement surface.

To test the corrosion resistance capacity of the coating under an acid/alkaline sewer environment, the corrosive liquid was repeatedly applied onto the surface for $5 \mathrm{~s}$ each time. The specimens were found to maintain their self-cleaning capacity when the liquid changed from water to acid and lye (see Figure 14). Very small decrease of the contact angle (CA) value was observed after the first 10 cycles, and the surface sustained a high CA after 120 cycles (Figure 14).

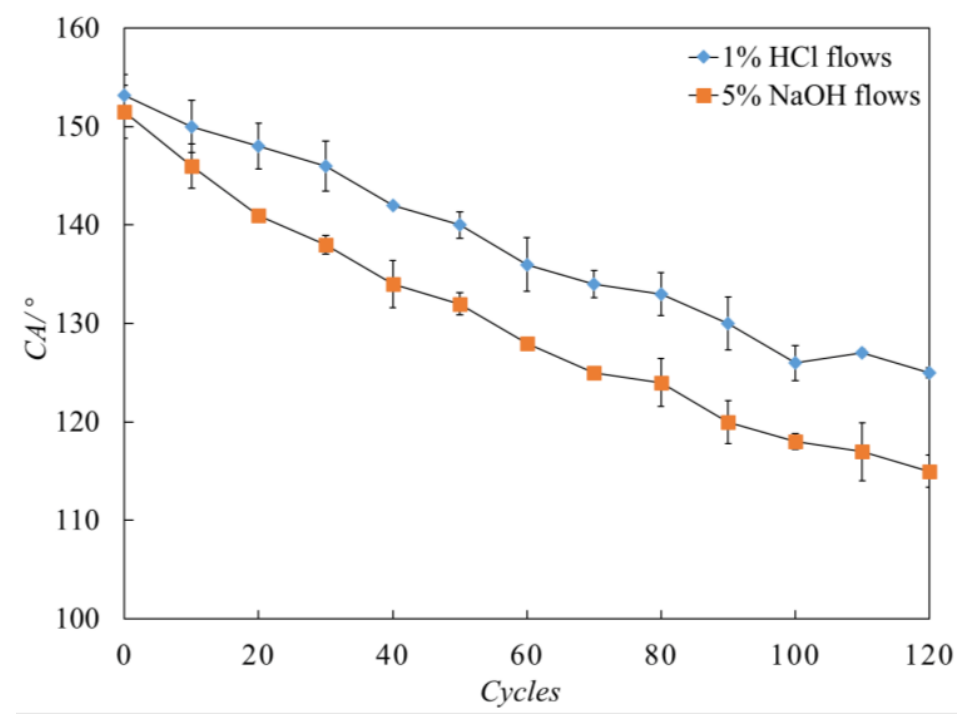

Figure 14. CA changes after 120 cycles.

\section{Discussion}

Our current study successfully prepared a robust $\mathrm{SiO}_{2}$ aerosol @ DGEBA coating based on the previous research [1,23-26]. The prepared coating presented excellent waterproof ability with a WCA greater than $150^{\circ}$ and a roll position less than $10^{\circ}$. Our straightforward superhydrophobic coating preparation process did not rely on a special mold or mesh, and it also avoided spraying silane coupling agent in large quantities, which meets the requirements of mass production and applications in underground engineering environments $[14,38,39]$. In this paper, the superhydrophobic coating was designed closely combining with trenchless pipeline rehabilitation work. DGEBA was used as the ideal superhydrophobic coating adhesive [40]. The coating showed good mechanical stability, self-cleaning, water discharge capacity, and anti-corrosive properties, which meet the complex underground water drainage pipeline environment [2]. In the corrosive environment, the $28 \mathrm{~d}$ compressive strength of 
samples under the protection of the coating was about $30.6 \%$ higher than those of the untreated samples, and the $28 \mathrm{~d}$ quality loss of the modified group was $71.4 \%$ lower than that of the untreated group.

Results demonstrated that this $\mathrm{SiO}_{2}$ aerosol @ DGEBA coating holds great application prospects in underground water drainage pipeline rehabilitation work. This kind of interdisciplinary research combines the superhydrophobic materials, cement-based materials, and engineering practice together, which may further promote the real-world applications of the superhydrophobic materials. Besides, further research on the durability of the coating under long-term water erosion and field tests in the real-world environment of a water drainage pipeline are needed in the future.

Author Contributions: Conceptualization, T.W. and C.Z.; methodology, T.W.; validation, T.W. and C.Z.; investigation, T.W.; resources, C.Z.; data curation, T.W.; writing-original draft preparation, T.W.; writing-review and editing, T.W. and C.Z.; supervision, C.Z.; project administration, C.Z.; funding acquisition, C.Z. All authors have read and agreed to the published version of the manuscript.

Funding: This research was funded by the National Key R\&D Program of China "Public security risk prevention and emergency response technology and equipment": Research and demonstration of urban underground utility tunnel safety prevention and control technology, grant number 2017YFC0805006.

Acknowledgments: The authors are very grateful to Zhiguang Guo for his invaluable advice and suggestions. The authors are very grateful to the technical support provided by Xiamen Anyue trenchless Engineering Technology Co., Ltd.

Conflicts of Interest: The authors declare no conflict of interest. The funders had no role in the design of the study; in the collection, analyses, or interpretation of data; in the writing of the manuscript, or in the decision to publish the results.

\section{References}

1. Muzenski, S.; Flores-Vivian, I.; Sobolev, K. Durability of superhydrophobic engineered cementitious composites. Constr. Build. Mater. 2015, 81, 291-297. [CrossRef]

2. Ma, B.S. Trenchless Pipeline Rehabilitation and Renewal Technology; China Communications Press: Beijing, China, 2014.

3. Ma, B.S. The Science of Trenchless Engineering; China Communications Press: Beijing, China, 2008; pp. 162-166.

4. Garcia, C.; Abraham, D.M.; Gokhale, S.; Iseley, T. Rehabilitation alternatives for concrete and brick sewers. Pract. Period. Struct. Des. Constr. 2002, 7, 164-173. [CrossRef]

5. Original Source: Zion Market Research, Found on Globenewswire, 4 September 2018. Available online: http://www.globenewswire.com (accessed on 4 September 2004).

6. Bour, D.L.; Brothers, L.E.; Caveny, W.J. Methods for Coating Pipe Comprising Using Cement Compositions Comprising High Tensile Strength Fibers and/or a Multi-Purpose Cement Additive. U.S. Patent No. 7,217,441, 15 May 2007.

7. Haile, T.; Nakhla, G.; Allouche, E.; Vaidya, S. Evaluation of the bactericidal characteristics of nano-copper oxide or functionalized zeolite coating for bio-corrosion control in concrete sewer pipes. Corros. Sci. 2010, 52, 45-53. [CrossRef]

8. Mulder, C.A.M.; Van Lierop, J.G. Preparation, densification and characterization of autoclave dried $\mathrm{SiO}_{2}$ gels. In Aerogels; Springer: Berlin/Heidelberg, Germnay, 1986; pp. 68-75.

9. Kim, S.; Seo, J.; Cha, J.; Kim, S. Chemical retreating for gel-typed aerogel and insulation performance of cement containing aerogel. Constr. Build. Mater. 2013, 40, 501-505. [CrossRef]

10. Gao, T.; Jelle, B.P.; Gustavsen, A.; Jacobsen, S. Aerogel-incorporated concrete: An experimental study. Constr. Build. Mater. 2014, 52, 130-136. [CrossRef]

11. Zorba, V.; Stratakis, E.; Barberoglou, M.; Barberoglou, E.; Tzanetakis, P. Biomimetic artificial surfaces quantitatively reproduce the water repellency of a lotus leaf. Adv. Mater. 2008, 20, 4049-4054. [CrossRef]

12. Nine, M.J.; Tung, T.T.; Alotaibi, F.; Tran, D.N.; Losic, D. Facile adhesion-tuning of superhydrophobic surfaces between "Lotus" and "Petal" effect and their influence on icing and deicing properties. Acs Appl. Mater. Interf. 2017, 9, 8393-8402. [CrossRef]

13. Gao, X.; Guo, Z. Mechanical stability, corrosion resistance of superhydrophobic steel and repairable durability of its slippery surface. J. Colloid Interface Sci. 2018, 512, 239-248. [CrossRef] 
14. Fürstner, R.; Barthlott, W.; Neinhuis, C.; Walzel, P. Wetting and self-cleaning properties of artificial superhydrophobic surfaces. Langmuir 2005, 21, 956-961. [CrossRef]

15. Zhang, F.; Zhao, L.; Chen, H.; Xu, S.; Evans, D.G.; Duan, X. Corrosion resistance of superhydrophobic layered double hydroxide films on aluminum. Angew. Chem. Int. Ed. 2008, 47, 2466-2469. [CrossRef]

16. Hong, X.; Gao, X.; Jiang, L. Application of superhydrophobic surface with high adhesive force in no lost transport of superparamagnetic microdroplet. J. Am. Chem. Soc. 2007, 129, 1478-1479. [CrossRef] [PubMed]

17. Horgnies, M.; Chen, J.J. Superhydrophobic concrete surfaces with integrated microtexture. Cem. Concr. Compos. 2014, 52, 81-90. [CrossRef]

18. Husni, H.; Nazari, M.R.; Yee, H.M.; Rohim, R.; Yusuff, A.; Ariff, M.A.M.; Junaidi, M.U.M. Superhydrophobic rice husk ash coating on concrete. Constr. Build. Mater. 2017, 144, 385-391. [CrossRef]

19. Liu, M.; Qing, Y.; Wu, Y.Q.; Liang, J.; Luo, S. Facile fabrication of superhydrophobic surfaces on wood substrates via a one-step hydrothermal process. Appl. Surf. Sci. 2015, 330, 332-338. [CrossRef]

20. Rezayi, T.; Entezari, M.H. Toward a durable superhydrophobic aluminum surface by etching and $\mathrm{ZnO}$ nanoparticle deposition. J. Colloid Interface Sci. 2016, 463, 37-45. [CrossRef]

21. Duan, Z.F.; Zhao, Z.; Luo, D.; Zhao, M.Q.; Zhao, G.Y. A facial approach combining photosensitive sol-gel with self-assembly method to fabricate superhydrophobic $\mathrm{TiO}_{2}$ films with patterned surface structure. Appl. Surf. Sci. 2016, 360, 1030-1035. [CrossRef]

22. Yang, N.; Li, J.C.; Bai, N.N.; Xu, L.; Li, Q. One step phase separation process to fabricate superhydrophobic PVC films and its corrosion prevention for AZ91D magnesium alloy. Mater. Sci. Eng. B 2016, 209, 1-9. [CrossRef]

23. Rezaei, S.; Manoucheri, I.; Moradian, R.; Pourabbas, B. One-step chemical vapor deposition and modification of silica nanoparticles at the lowest possible temperature and superhydrophobic surface fabrication. Chem. Eng. J. 2014, 252, 11-16. [CrossRef]

24. Darmanin, T.; de Givenchy, E.T.; Amigoni, S. Guittard, Superhydrophobic surfaces by electrochemical processes. Adv. Mater. 2013, 25, 1378-1394. [CrossRef]

25. Wu, Y.; Zhao, M.; Guo, Z. Robust, heat-resistant and multifunctional superhydrophobic coating of carbon micro flowers with molybdenum trioxide nanoparticles. J. Colloid Interface Sci. 2017, 506, 649-658. [CrossRef]

26. Wong, H.S.; Barakat, R.; Alhilali, A.; Saleh, M.; Cheeseman, C.R. Hydrophobic concrete using wastepaper sludge ash. Cem. Concr. Res. 2015, 70, 9-20. [CrossRef]

27. She, W.; Wang, X.; Miao, C.; Zhang, Q.; Zhang, Y.; Yang, J.; Hong, J. Biomimetic superhydrophobic surface of concrete: Topographic and chemical modification assembly by direct spray. Constr. Build. Mater. 2018, 181, 347-357. [CrossRef]

28. Arabzadeh, A.; Ceylan, H.; Kim, S.; Gopalakrishnan, K.; Sassani, A.; Sundararajan, S.; Taylor, P.C. Superhydrophobic coatings on Portland cement concrete surfaces. Constr. Build. Mater. 2017, 141, $393-401$. [CrossRef]

29. Young, T.J.; Jackson, J.; Roy, S.; Ceylan, H.; Sundararajan, S. Tribological behavior and wettability of spray-coated superhydrophobic coatings on aluminum. Wear 2017, 376, 1713-1719. [CrossRef]

30. ASTM C150. Standard Specification for Portland Cements; American Society for Testing and Materials; ASTM International: West Conshohocken, PA, USA, 2003.

31. Zhou, W.; Kong, Y. Centrifugally cast manhole technology applied to the world's largest manhole trenchless rehabilitation project. China Trenchless Technol. 2015, 3, 51-54.

32. ASTM C642-13. Standard Test Method for Density, Absorption, and Voids in Hardened Concrete; West ASTM International: West Conshohocken, PA, USA, 2013.

33. Jiang, H.; Sun, L.; Zhang, Y.; Meng, F.; Zhang, W.; Zhao, C. Estrogenic activity research of a novel fluorinated bisphenol and preparation of an epoxy resin as alternative to bisphenol A epoxy resin. Eur. Polym. J. 2018, 108, 507-516. [CrossRef]

34. Liu, M.; Li, J.; Hou, Y.; Guo, Z. Inorganic adhesives for robust superwetting surfaces. ACS Nano 2017, 11, 1113-1119. [CrossRef]

35. Wang, Z.; Gao, X.; Wen, G.; Tian, P.; Zhong, L.; Gou, X.; Guo, Z. Robust silicon dioxide@ epoxy resin micronanosheet superhydrophobic omnipotent protective coating for applications. Colloids Surf. A Physicochem. Eng. Asp. 2018, 550, 9-19. [CrossRef]

36. Lu, Y.; Sathasivam, S.; Song, J.; Crick, C.R.; Carmalt, C.J.; Parkin, I.P. Robust self-cleaning surfaces that function when exposed to either air or oil. Science 2015, 347, 1132-1135. [CrossRef] 
37. Cabral-Fonseca, S.; Correia, J.R.; Custódio, J.; Silva, H.M.; Machado, A.M.; Sousa, J. Durability of FRP-concrete bonded joints in structural rehabilitation: A review. Int. J. Adhes. Adhes. 2018, 83, 153-167. [CrossRef]

38. Song, J.; Zhao, D.; Han, Z.; Xu, W.; Lu, Y.; Liu, X.; Liu, B.; Carmalt, C.J.; Deng, X.; Parkin, I.P. Super-robust superhydrophobic concrete. J. Mater. Chem. A 2017, 5, 14542-14550. [CrossRef]

39. Song, J.; Li, Y.; Xu, W.; Liu, H.; Lu, Y. Inexpensive and non-fluorinated superhydrophobic concrete coating for anti-icing and anti-corrosion. J. Colloid Interface Sci. 2019, 541, 86-92. [CrossRef] [PubMed]

40. Arabzadeh, A.; Ceylan, H.; Kim, S.; Gopalakrishnan, K.; Sassani, A. Superhydrophobic coatings on asphalt concrete surfaces: Toward smart solutions for winter pavement maintenance. Transp. Res. Rec. 2016, 2551, 10-17. [CrossRef]

Publisher's Note: MDPI stays neutral with regard to jurisdictional claims in published maps and institutional affiliations.

(C) 2020 by the authors. Licensee MDPI, Basel, Switzerland. This article is an open access article distributed under the terms and conditions of the Creative Commons Attribution (CC BY) license (http://creativecommons.org/licenses/by/4.0/). 